\title{
Phosphorus Outsourcing to Lake Kinneret (Israel) is Significantly Affected by Climate Conditions
}

\author{
Moshe Gophen* \\ Migal, Scientific Research Institute, P.O.B. 831, Kiryat Shmone (11016), Israel \\ ${ }^{\star}$ Corresponding author: Moshe Gophen, Migal, Scientific Research Institute, P.O.B. 831, Kiryat Shmone (11016), Israel; Email: Gophen@migal.org.il
}

Received: September 18, 2021; Accepted: September 22, 2021; Published: September 29, 2021

Long-term records [1-4] in the drainage basin of Lake Kinneret has indicated that since the mid-1980`s, significant changes in climate conditions have occurred, and trends of dryness in the Kinneret drainage basin have been documented, including a temperature increase and precipitation decline. The precipitation decline and consequently the reduction in river discharge resulted in a decrease in TP flux into Lake Kinneret. The known external TP sources are natural bedrock erosion, dust deposition, and anthropogenic intervention in the drainage basin, as well as soil degradation and agriculturaleco-tourism developments within the Hula Valley. Among internal sourcing of Phosphorus in Lake Knneret, reductive conditions and microbial activity in the anoxic hypolimnion sediments are significant during the $8^{\text {th }}$ month of stratification period. The major contribution within the external TP inputs is due to the erosive action which is dependent on river discharge. The TP concentrations in the Jordan River were found to be significantly related to the discharge ranges. The river discharge has been a consequence of climate conditions, of precipitation. During the 1950`s the Hula natural wetlands and old Lake Hula (part of the Kinneret drainage basin) was drained and the land was converted to agricultural development and consequently the ecological features of the Hula Valley were modified. Nutrient fluxes downstream into lake Kinneret were predicted. The significance enhancement of the impact of precipitation and discharge fluctuations on TP outsourcing through erosive action was documented: higher and lower discharge enhances and reduces TP load, respectively. The total TP flushing range from the Hula Valley peat soil through the subterranean channels where TP is migrated are not precisely known but probably Lake Kinneret as collectors of those is excluded. Long-term records of TP concentrations in headwaters and potential resources in the Hula Valley confirmed the significant influence of climate conditions on the outsourcing of TP. The impacts of agricultural development, external fertilizer loads and migratory cranes in the winter (50,000 during 5 months) are probably insignificant. As a result of the old lake Hula and wetland drainage, the unique natural composition of exceptionally diverse fauna and flora was devastated. The newly created arable land became a source of income to the residents of northern Israel. For 40 years, it was successfully cultivated, agricultural products (mostly cotton, corn, alfalfa, and vegetables) were economically produced, and nutrient flux into Lake Kinneret did not threaten the lake's water quality. Nevertheless, as a result of inappropriate management, enhancement of dust storms devastating fresh sprout-germinates and blocking of drainage canals, irrigation methods were not appropriate for optimal soil moisture management, soil fertility decreased and Ground Water Table (GWT) was lowered. The soil structure of the upper layer became oxidized and deteriorated, heavy dust storms became frequent, and the soil surface subsided $(7-10 \mathrm{~cm} /$ year). Underground fires occurred often. increased rodent population outbreaks which caused severe damage to agricultural crops and to the stability of drainage canal banks. Moreover, agricultural cultivation of $8 \%$ in the middle of Hula Valley land was gradually abandoned. Therefore, during 1990-1997, the entire drainage area underwent a reclamation project, Hula Reclamation Project (HRP). The project was aimed primarily at decreasing the nutrient fluxes from the Hula Valley soil while implementing modern irrigation methods and innovation of economical land use accompanied by integrate eco-tourism. The HRP comprised several operational stages: increasing the soil moisture by elevating the GWT, changing the irrigation method, renewing the drainage system in the entire valley, and creating a new shallow lake namely 'Agmon-Hula'. This shallow lake was designed to be a collector for the entire valley and to provide an appropriate service for eco-tourism. A plastic sheet (4-mm thickness) was placed vertically $(0-4.5 \mathrm{~m})$ along $2.8 \mathrm{~km}$, crossing the valley in an east-west position, to partition the southern part of the valley aimed at prevention of underground leakage of pollutants into Lake Kinneret. Lake Agmon was proposed to support sufficient volume for the collection of peat soil-drained-nutrient-rich water effluent and was also mixed with fresh Jordan River water to prevent deterioration of water quality. Nutrient-rich polluted water from Lake Agmon-Hula was transferred for irrigation usage outside the Kinneret drainage basin. Natural attractions (migratory Cranes) were designed for observational touring of the aquatic vegetation landscape, bird watching and sport fishing recreation. The original design was successfully implemented, and crane wintering provided an attractive experience for tourists.

\section{Conclusive Remarks}

The Kinneret region has undergone changes in climate conditions, prominently dryness. These changes enhanced processes of decline in rainfall-river discharge, and were accompanied by changes in nutrient dynamics and decreases in input concentrations. These modifications in nutrient dynamics were not likely to have been affected by the presence of Cranes in the Hula Valley. The seasonal changes in TP 
concentration of the Agmon-Hula effluent are due to the onset and offset of submerged macrophytes. The fate of prominent part of the movable phosphorus produced in the Hula Valley ecosystem is unclear. Phosphorus input into Lake Kinneret through river discharge is affected primarily by climate change. The concentration and consequently total load of phosphorus in the outflow of Lake AgmonHula by is significantly affected by submerged macrophytes and, to a lesser extent by cranes.

\section{References}

1. Gophen M, Levanon D (eds) (1993-2006) Hula Project, Annual Reports: MigalSientific Research Institute, Jewish National Fund (Keren Kayemet LeIsrael), US Forestry Service International Project, Israeli Water Authority.

2. Gonen E (ed) (2007) Hula Project Annual Report, Jewish National Fund (Keren Kayemet LeIsrael) Migal-Scientific Research Institute and Israeli Water Authority, pg: 133.

3. Barnea I (ed) (2008) Hula Project Annual Report, Jewish National Fund (Keren Kayemet LeIsrael) Migal-Scientific Research Institute and Israeli Water Authority pg: 159

4. Barnea I (ed) (2008-2018) Hula Project Annual Report, Jewish National Fund (Keren Kayemet LeIsrael) Migal-Scientific Research Institute and Israeli Water Authority pg: 232.

\section{Citation:}

Gophen M (2021) Phosphorus Outsourcing to Lake Kinneret (Israel) is Significantly Affected by Climate Conditions. Geol Earth Mar Sci Volume 3(4): 1-2. 